$\xi$

\title{
Portfolio Selection and Post Optimality Test Using Goal Programming
}

\author{
Darsha Panwar ${ }^{1}$, Manoj Jha ${ }^{2}$, Namita Srivastava ${ }^{3}$ \\ ${ }^{123}$ Department of Mathematics, Maulana Azad National Institute of Technology, Bhopal (M.P.), India \\ *Corresponding author E-mail: panwar.darsha@gmail.com
}

\begin{abstract}
In a practical portfolio planning process the investment decision to be taken by an investor is not simple and is influenced by several other constraints like stock price, co-moment with market, return with respect to risk, past performance and so many. In this purview, a hybrid approach is employed for portfolio selection which combines multiple methodologies like investor topology, cluster analysis, analytical hierarchy process (AHP) for ranking the assets and biogeographic-based optimization (BBO). Furthermore, with the help of goal programming (GP), performing post optimality test for betterment the result which is obtained by BBO. In the goal programming, objective is to be minimizing the weighted deviations of desire goals. Weighted deviation is known as achievement, which has two branches namely over achievement and under achievement.
\end{abstract}

Keywords. Analytical hierarchy process, Cluster analysis, Biogeographical-based optimization, Post optimality analysis, Goal programing. MSC. 65K10, 62P05, 94D05.

\section{Introduction}

Selection of stock is not an easy task. The investment of stock does not guarantee since the decision requires to be made today with missing information about future price. To resolving the problem of portfolio selection, numerous models have been introduced.

The problem of portfolio selection was initially presented by Professor Harry Markowitz [9]. He proposed a Markowitz model for portfolio selection that is because investing in more than one stock is less risky than investing in a single stock. Konno and Yamazaki [10] introduced an improved version of Markowitz model both computationally and theoretically, and the risk is calculated as mean absolute deviation (MAD). Speranza [13] presented a linear programming model. In this model, the risk has been measured by semi absolute deviation method.

Hasuike and Katagiri [18] considered a portfolio selection problem using investor's subjectivity and then applied sensitivity analysis for changing the subjectivity. Portfolio selection is done using fuzzy programming problem. Stoyan and Kwon [16] addressed a complex stochastic goal mixed-integer programming model for stock and bond portfolio. Masmoudi and Abdelaziz [14] presented a bi-objective stochastic programming, portfolio optimization model, which is solved by goal programming with the objectives return and risk. Ghahtarani and Najafi [3] presented robust optimization goal programing for portfolio selection problem. Siew and Hoe [12] applied a goal programming model using mean return and tracking error for optimizing portfolio. Tamiz and Azmi et. al. [15] proposed the extended factors of stocks and applied goal programming for portfolio selection. They applied three alternatives of goal programming namely weighted, lexicographic and minimax approach.

From the literature survey, we conclude that goal programing is the most widely used optimization technique and applied for portfolio optimization. Sensitivity analysis or post optimality test has not been considered much for portfolio optimization while it is important for real situation.

In this approach, a portfolio selection with multiple methodology and post optimality test is employed. Firstly, X-means algorithm is applied for clustering the stocks into three different clusters such as high return stock, less risky stock and liquid stock as investors are divided into three main categories according to investor behavioral survey [4]. In X-means, there is no need to specify the number of clusters. Then by applying AHP, socks are valuated under some new features such as relative strength index (RSI), coefficient of variation (CV) and some basic features return, risk, liquidity, alpha and beta. The optimization is done using biogeographic-based optimization with eight objective functions return, risk, liquidity, relative strength index (RSI), coefficient of variation $(\mathrm{CV})$, alpha, beta and AHP weighted score. After optimization post, optimality test performed using goal programming. The daily closing price, number of shares and turnover rate for all the selected 15 stocks are taken from BSE, 
Bombay stock exchange, Mumbai, India, (from February-15 to January-16).

This paper is organized as follows: Segment 2 contains a description of research methodology, BBO algorithm and its working process with reference to each of the eight objectives, namely return, risk, liquidity, relative strength index, coefficient of variation, alpha, beta and AHP weighted score. Segment 3, presents the numerical illustration and post optimality test, concluding remarks are given in segment 4.

\section{Methodology}

Following systematic strategy used for solving the multiobjective linear programming problem

\section{A. Investor behavior pattern}

Generally, investor is focused only on basic factors like return, risk and liquidity. However, there are some new and important factors to consider before selecting the stocks. These factors are alpha, beta, relative strength index (RSI) and coefficient of variation $(\mathrm{CV})$.

- J.Welles Wilder introduced relative strength index in 1978, it calculates the present and past performance of a stock because of today's closing prices. RSI generally belongs to the range 30-70.

- Coefficient of variation helps to evaluate the value of instability relative to the return rate.

- $\quad$ Alpha-coefficient compares return with respect to risk.

- Beta-coefficient shows volatility or systematic risk of a stock or portfolio as compare to the market. Beta 1 shows that the stock's price changes with the market. Beta Greater than 1 shows higher volatility and less than 1 shows less volatility than the market.

\section{B. Cluster}

Different investor has different approach towards selecting stocks. Stocks divided into three groups' namely high return stocks, less risky stocks and liquid stocks according to the investors' interest. Cluster analysis is a technique to grouping similar data that is different from another group data. X-means [6] algorithm is used for clustering. It is an extended version of K-means, which attempts to automatically determine the number of clusters. It starts with just one centroids and then iteratively increases the centroid as required.

\section{AHP}

AHP technique developed by Thomas L. Saaty [17], which is a multi-criterion decision-making (MCDM) tool. It has a particular application in group decision making. There are three main steps of AHP for ranking the object:

1. Hierarchy structure design

2. Weight analysis

3. Consistency proof

Figure 1 shows the four level hierarchy structure of AHP. Firstly, form a pairwise comparison matrix for each criterion with respect to its parent criteria.

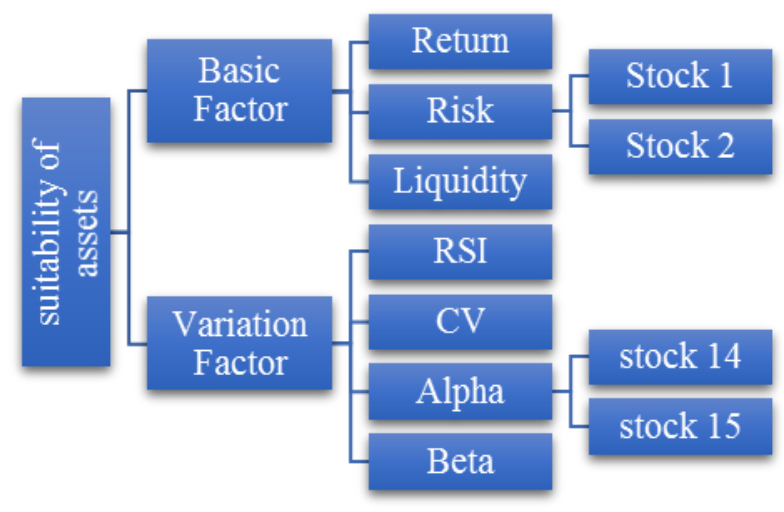

Fig.1: Hierarchy Structure

The judgmental matrix $\mathrm{A}$ is formed by as follows:

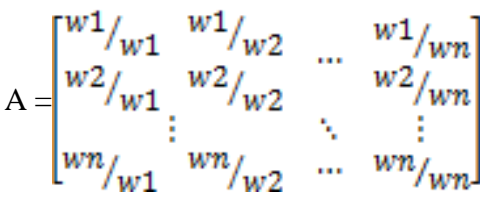

Where ' $w$ ' is known as weight of the objects. The consistency index $(\mathrm{CI})$ for each $\mathrm{n}^{\text {th }}$ order matrix is calculated as:

$\mathrm{CI}=\left(\lambda_{\max }-\mathrm{n}\right) /(\mathrm{n}-1)$

$\lambda_{\max }$ is the highest Eigen value of the matrix A.

The consistency ratio (CR) is calculated as:

$\mathrm{CR}=\mathrm{CI} / \mathrm{RI}$

Where RI the random index be determined by on the order of the matrix.

The acceptable is CR is less than or equal to 0.10. Inconsistencies exist and pairwise comparisons need revision when $\mathrm{CR}>0.01$.

\section{Portfolio selection model}

For stock selection and optimization Biogeography-based optimization algorithm (BBO) is used, which has been explained in [8]. $\mathrm{BBO}$ is population based algorithm and introduced by Dan Simon in 2008 [7]. It is evolutionary algorithm based on the concept of migration and mutation.

For solving multi-objective programming problem following parameter are used:

$\mathrm{n}=15$ stocks (population size)

$\mathrm{H}=50$ (habitat)

$\mathrm{H}_{\mathrm{j}}=\left[\operatorname{SIV}_{\mathrm{j} 1}, \operatorname{SIV}_{\mathrm{j} 2}, \ldots, \mathrm{SIV}_{\mathrm{j} 15}\right], \mathrm{j}=1,2, \ldots, 50$ (here SIVs represents proportion of the stocks)

For HSI calculate below equation for each $\mathrm{H}$

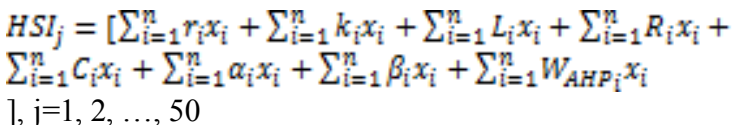

Set maximum immigration rate $(\mathrm{I})=1$ (assume habitat is empty) and

Maximum emigration rate $(\mathrm{E})=1$ (assume habitat contains all 15 stock).

Immigration rate $\lambda_{\mathrm{s}}=\mathrm{I}(1-\mathrm{s} / 15)$

Emigration rate $\mu_{\mathrm{s}}=\mathrm{E}(\mathrm{s} / 15)$ 
Where $\mathbf{s}$ is the number of stock and $\lambda_{s}$ decides whether to improve each SIV in $i^{\text {th }}$ solution and $\mu_{s}$ of other habitat decides which solution should migrate that particular selected SIV. After that process, apply mutation for improving SIVs because of habitat's probability.

Mutation rate having s species: $\mathrm{m}(\mathrm{s})=\mathrm{m}_{\max }\left(\left(1-\mathrm{P}_{\mathrm{s}}\right) / \mathrm{P}_{\max }\right)$

Where $\mathrm{m}_{\max }=$ maximum mutation rate which is user defined parameter.

$\mathrm{P}_{\max }=$ maximum probability of species

$\mathrm{P}_{\mathrm{s}}=$ probability of HSI exactly having s species

$\mathrm{P}_{\mathrm{i}}=\left\{\begin{array}{lr}-\left(\lambda_{\mathrm{i}}+\mu_{\mathrm{i}}\right) P_{\mathrm{i}}+\mu_{\mathrm{i}+1} P_{\mathrm{i}+1} & i=0 \\ -\left(\lambda_{\mathrm{i}}+\mu_{\mathrm{i}}\right) P_{\mathrm{i}}+\lambda_{\mathrm{i}-1} P_{\mathrm{i}-1}+\mu_{\mathrm{i}+1} P_{\mathrm{i}+1}, 1 \leq i \leq 15 \\ -\left(\lambda_{\mathrm{i}}+\mu_{\mathrm{i}}\right) P_{\mathrm{i}}+\lambda_{\mathrm{i}-1} P_{\mathrm{i}-1} & i=15\end{array}\right.$

Now first iteration is complete, loop can be terminated after defined number of iteration.

\section{Portfolio Selection Problem}

The multi-objective portfolio selection problem with eight objective functions such as return, risk, relative strength index, coefficient of variation, earning yield, price to earnings growth ratio, AHP weight and some notations are introduced as follows:

$r_{i}$ s return of the $i^{\text {th }}$ stock,

$L_{i}$ : liquidity of the $i^{\text {th }}$ stock,

$x_{i}:$ the proportion of the total fund invested in the $i^{\text {th }}$ stock,

$b_{i}:$ the binary variable indicating whether the $i^{\text {th }}$ stock, contained in the portfolio or not,

\section{i.e. $b_{i}=\left\{1_{2}\right.$ if ith stock contained in portfolio \\ $0_{\mathrm{s}}$ if not containing in portfolio}

$k_{i}:$ risk of thei $i^{t n}$ stock,

$R_{i}$ : relative strength index of the $i^{\text {th }}$ stock,

$C_{i}:$ coefficient of variation of the $i^{\text {th }}$ stock,

$W_{A H P i}$ the AHP weight of the $i^{t n}$ stock,

$\alpha_{i}:$ alpha-coefficient of the $i^{\text {th }}$ stock,

$\beta_{i}$ : beta-coefficient of the $i^{\text {th }}$ stock,

$u_{i}:$ the maximum fraction of the $i^{\text {th }}$ stock,

$l_{i}:$ the minimum fraction of the $i^{\text {th }}$ stock,

$n$ : total number of stocks in the cluster,

a : number of stocks in the selected portfolio

Objective functions are as follows:

1) Return

The return of the portfolio is written as:

$f_{1}(x)=\sum_{i=1}^{n} r_{i} x_{i}$

Where $r_{\mathrm{i}}=\frac{1}{12} \sum_{\mathrm{i}=1}^{12} r_{\mathrm{it}}$.

2) Risk

The semi-absolute deviation of return of the portfolio below the expected return over the past period $\mathrm{t}$,

$\mathrm{t}=1,2, \ldots \mathrm{T}$, can be written as:

$k_{i}(x)=\left|\min \left\{0_{0} \sum_{i=1}^{n}\left(r_{i t}-r_{i}\right)\right\} x_{i}\right|=\frac{\left|\sum_{i=1}^{n}\left(r_{i t}-r_{i}\right) x_{i}\right|+\sum_{i=1}^{n}\left(r_{i}-r_{i t}\right) x_{i}}{2}$

Consequently, the expected semi-absolute deviation of return of the portfolio $\quad \mathrm{x}=\left(x_{1} x_{2}, x_{\mathrm{g}, \ldots} x_{n}\right)$ below the expected return becomes

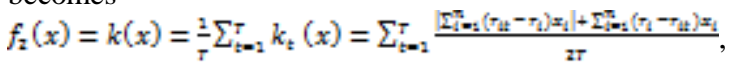

Where $\mathrm{k}(\mathrm{x})$ represents portfolio risk.

\section{3) Liquidity}

Liquidity is measured as the possibility of transformation of an investment into cash without affecting the asset's price. It is a known fact that turnover rates of assets cannot be exactly forecasted. For this, we use the idea of possibility theory, which was introduced by Zadeh [11] and improved by Dubois and Prade [5] Fuzzy number $\mathrm{F}$ is known as trapezoidal with tolerance interval $[a, b, \alpha, \beta]$, if its membership function defined as:

$\mu_{F}= \begin{cases}1-\frac{a-t}{\alpha} & \text { if }(a-a) \leq t \leq a \\ 1 & \text { if } a \leq t \leq b \\ 1-\frac{t-b}{\beta} & \text { if } b \leq t \leq(b+\beta) \\ 0 & \text { otherwise. }\end{cases}$

Let the turnover rate of the $i^{\text {th }}$ stock is denoted by a trapezoidal fuzzy number $L_{i}=\left(L_{a j,} L_{b_{i x} x} \alpha_{i x} \beta_{i}\right)$. Then, the portfolio turnover rate is given as $\sum_{\mathrm{i}=1}^{n} L_{\mathrm{i}} x_{\mathrm{i}}$. The turnover rate of the portfolio by the fuzzy extension principle [11] is given as

$f_{a}(x)=\sum_{i=1}^{n} L_{i} x_{i}=\sum_{i=1}^{n}\left(\frac{L_{a i}+L_{b f}}{2}+\frac{\beta_{i}-\alpha_{i}}{6}\right) x_{i}$.

4) Relative strength index (RSI)

The RSI of the portfolio is written as:

$f_{4}(x)=\sum_{\mathrm{i}=1}^{n} R_{\mathrm{i}} x_{\mathrm{i}}$,

Where $R_{i}=100-\frac{100}{1+\text { avg }}$ and avg $g_{i}=\frac{\text { avg gain }}{\text { avg loss }}$.

5) Coefficient of variation $(\mathrm{CV})$

The $\mathrm{CV}$ of the portfolio is written as:

$f_{5}(x)=\sum_{i=1}^{n} C_{i} x_{i}$,

Where $c_{i}=\frac{s D_{i}}{\text { return }}$ of the $i^{\text {th }}$ stock.

6) Alpha-coefficient $(\alpha)$

The $\alpha$ of the portfolio is written as:

$f_{6}(x)=\sum_{i=1}^{n} \alpha_{i} x_{i}$,

Where $\alpha_{i}$ is the alpha-coefficient of the $i^{\text {th }}$ stock.

7) Beta-coefficient $(\beta)$

The $\beta$ of the portfolio is written as:

$f_{7}(x)=\sum_{\mathrm{i}=1}^{n} \beta_{\mathrm{i}} x_{\mathrm{i}}$,

Where $\beta_{i}$ is the beta-coefficient of the $i^{\text {th }}$ stock.

8) AHP weight

The AHP weight of the portfolio is written as:

$f_{\mathrm{s}}(x)=\sum_{\mathrm{i}=1}^{\mathrm{n}} w_{\text {AHPi }} x_{\mathrm{i}}$

Where $W_{A H P i}$ is weight of $i^{\text {th }}$ stock.

Constraints:

Investment economical restriction on the stocks:

9) Sum of proportion of stocks should be 1

$\sum_{i=1}^{n} x_{i}=1$

10) Number of stocks held in a portfolio:

$\sum_{i=1}^{n} b_{i}=a$

11) The maximum percentage of the investment which can be invested in a stock:

$x_{i} \leq u_{i} b_{i} \quad i=1,2_{z} n$,

12) The minimum percentage of the investment which can be invested in a stock:

$x_{i} \geq l_{i} b_{i}, \quad i=1,2_{x=n} n$, 
The upper and lower bounds have been taken to avoid too many large investments and in the same manner too many small investments.

\section{The decision problem:}

$$
\begin{aligned}
& \max _{1}(x)=\sum_{\mathrm{i}=1}^{n} r_{\mathrm{i}} x_{\mathrm{i}} \\
& \min _{2}(x)=\sum_{\mathrm{i}=1}^{n} k_{\mathrm{i}} x_{\mathrm{i}} \\
& \max _{\mathrm{a}}(x)=\sum_{\mathrm{i}=1}^{n} L_{\mathrm{i}} x_{\mathrm{i}} \\
& \max f_{4}(x)=\sum_{\mathrm{i}=1}^{n} R_{\mathrm{i}} x_{\mathrm{i}} \\
& \max f_{5}(x)=\sum_{\mathrm{i}=1}^{n} C_{\mathrm{i}} x_{\mathrm{i}} \\
& \max f_{6}(x)=\sum_{\mathrm{i}=1}^{n} \alpha_{\mathrm{i}} x_{\mathrm{i}} \\
& \max f_{7}(x)=\sum_{\mathrm{i}=1}^{n} \beta_{\mathrm{i}} x_{\mathrm{i}} \\
& \max _{\mathrm{g}}(x)=\sum_{\mathrm{i}=1}^{n} W_{A H P \mathrm{i}} x_{\mathrm{i}}
\end{aligned}
$$

subject to

$\sum_{i=1}^{n} x_{i}=1$

$\sum_{i=1}^{n} b_{i}=a$,

$x_{i} \leq u_{i} b_{i}, i=1,2_{x} n_{p}$

$x_{\mathrm{i}} \geq l_{\mathrm{i}} b_{i}, \hat{i}=1,2_{x, \ldots s} n_{v}$

$x_{i} \geq 0, i=1,2 \ldots n s$,

$b_{i} \in\{0,1\} x=1,2, \ldots, n$.

\section{Numerical Illustration}

The results of an experimental study built on the data set of 147 assets registered in BSE, Mumbai, India, (from February-15 to January-16) are as follows:

\section{A. Cluster analysis}

For performing cluster analysis, X-means tool of the Rapid Miner version 5.2 software are used. The initial distribution of first centroid is performed by k-means clustering. The result of the Xmeans algorithm is shown in table 1.

Table1. Cluster result

\begin{tabular}{|l|l|l|l|}
\hline Parameters & $\begin{array}{l}\text { Cluster 1 (46 } \\
\text { stocks) }\end{array}$ & $\begin{array}{l}\text { Cluster 2 (78 } \\
\text { stocks) }\end{array}$ & $\begin{array}{l}\text { Cluster } \\
\text { (23stocks) }\end{array}$ \\
\hline $\begin{array}{l}\text { average } \\
\text { return }\end{array}$ & 0.0441 & 0.0154 & 0.0731 \\
\hline average risk & 0.0547 & 0.0344 & 0.0744 \\
\hline turnover rate & 0.0010 & 0.0005 & 0.0010 \\
\hline Category & Liquid & less risky & high return \\
\hline
\end{tabular}

As per investors' behavior about risk, return and liquidity stocks divided into 3 categories.

1) Cluster 1: Stocks having high liquidity as compare to other cluster grouped in this cluster. This cluster is for those investors who are interested in liquid stocks and medium risk.

2) Cluster 2: contains high return stock as compared to other clusters. This cluster is for those investors who focused only on maximum return.

3) Cluster 3: contain less risky stocks as compared to other clusters. This cluster is for those investors who are risk averse.

Symbolic representations of stocks from each cluster are shown in table 2 .

Table 2: Stocks for each cluster

\begin{tabular}{|l|l|l|l|}
\hline Symbol & Cluster 1 & Cluster 2 & Cluster 3 \\
\hline S1 & Whbrady & Blue Star & Kinetic Eng. \\
\hline S2 & Nelco Ltd. & Great Estate & Tokyo Plast \\
\hline S3 & Nocil Ltd & Swaraj Engine & Force Motor \\
\hline S4 & Ceat Limited & Bajfinance & Kg Denim \\
\hline S5 & Nucleus S/w Exports Ltd. & Finolex Ind. & Zenith Fiber \\
\hline S6 & Sauras.Cem. & Bharat Pet. & Jenson Nicolson \\
\hline S7 & Fedder.Llyod & Lakshmi Mill & NIIT Ltd. \\
\hline S8 & Dew Ltd. & Jsw steel & Tata Elxsi \\
\hline S9 & Eveready Ind. India Ltd. & Pel & Century Ext \\
\hline S10 & Himachal Fertilizer & Swan Eng & Jasch Indust \\
\hline S11 & Timex Group & Pfizer Ltd. & Medi-caps \\
\hline S12 & Camph.\& All & Sri Adhikari Brothers Tel. Net. Ltd. & Pas.Acrylon \\
\hline S13 & Andhra Petro & Kajaria Cer. & Modi Rubber \\
\hline S14 & Sha Eng Pla & Asian Paints & Mafatlal Ind \\
\hline S15 & Majestic Aut & Lic Housing Finance & Panyam Cement \\
\hline
\end{tabular}

B. Numerical calculation of AHP weights

In this segment under the criteria and sub-criteria in AHP, stocks ranked according to the investor preference. The weights are given in table 3.

Table 3. Weight of criteria and sub-criteria

\begin{tabular}{|l|l|l|l|}
\hline Criteria & Weight & sub-criteria & Weight \\
\hline Basic factor & 0.6500 & Risk & 0.2321 \\
\cline { 3 - 4 } & & Return & 0.1857 \\
\hline & & Liquidity & 0.2321 \\
\cline { 3 - 4 } & & Relative Strength Index & 0.0700 \\
\hline Valuation factor & Coefficient of Variation & 0.0700 \\
\cline { 3 - 4 } & Alpha & 0.1050 \\
\cline { 3 - 4 } & & Beta & 0.1050 \\
\hline
\end{tabular}


Table 4-6 represents the input data for all three clusters.

Table 4: Input data for cluster 1

\begin{tabular}{|c|c|c|c|c|c|c|c|c|}
\hline Stocks & Return & Risk & RSI & $\mathrm{CV}$ & Alpha & Beta & Liquidity & AHP-weight \\
\hline S2 & 0.0296 & 0.0638 & 50.6893 & 5.2433 & 0.0515 & 2.2247 & 0.0021 & 0.0598 \\
\hline S3 & 0.0369 & 0.0471 & 52.5398 & 3.0668 & 0.0615 & 2.4884 & 0.0019 & 0.0639 \\
\hline S4 & 0.0314 & 0.0544 & 50.6261 & 4.8066 & 0.0382 & 0.6942 & 0.0016 & 0.0524 \\
\hline S6 & 0.0512 & 0.0620 & 51.4297 & 3.8625 & 0.0955 & 4.4973 & 0.0010 & 0.0677 \\
\hline S7 & 0.0323 & 0.0661 & 50.8229 & 4.9407 & 0.0711 & 3.9288 & 0.0009 & 0.0582 \\
\hline S8 & 0.0417 & 0.0366 & 52.1835 & 2.2204 & 0.0641 & 2.2632 & 0.0009 & 0.0608 \\
\hline S11 & 0.0673 & 0.0483 & 55.1665 & 1.9584 & 0.0753 & 0.8048 & 0.0007 & 0.0581 \\
\hline S12 & 0.0653 & 0.0486 & 53.9227 & 1.7890 & 0.0876 & 2.2667 & 0.0007 & 0.0624 \\
\hline S13 & 0.0308 & 0.0592 & 49.3334 & 4.6172 & 0.0668 & 3.6529 & 0.0006 & 0.0553 \\
\hline S14 & 0.0628 & 0.0402 & 56.8973 & 1.5707 & 0.0864 & 2.3939 & 0.0006 & 0.0649 \\
\hline S15 & 0.0556 & 0.0669 & 49.7316 & 3.1074 & 0.0657 & 1.0232 & 0.0006 & 0.0504 \\
\hline
\end{tabular}

Table 5: Input data for cluster 2

\begin{tabular}{|c|c|c|c|c|c|c|c|c|}
\hline Stocks & Return & Risk & RSI & CV & Alpha & Beta & Liquidity & AHP-weight \\
\hline S1 & 0.0110 & 0.0151 & 51.2555 & 3.7010 & 0.0165 & 0.5584 & 0.0000 & 0.0499 \\
\hline S3 & 0.0111 & 0.0172 & 51.0755 & 3.8100 & 0.0199 & 0.8866 & 0.0001 & 0.0547 \\
\hline S6 & 0.0192 & 0.0190 & 52.7992 & 2.5065 & 0.0284 & 0.9364 & 0.0001 & 0.0660 \\
\hline S7 & 0.0017 & 0.0197 & 49.6072 & 31.8555 & 0.0089 & 0.7298 & 0.0001 & 0.0523 \\
\hline S8 & 0.0058 & 0.0203 & 50.0006 & 9.4639 & 0.0030 & -0.2801 & 0.0004 & 0.0583 \\
\hline S11 & 0.0128 & 0.0218 & 50.8221 & 4.1963 & 0.0161 & 0.3333 & 0.0001 & 0.0465 \\
\hline S12 & 0.0349 & 0.0220 & 56.2961 & 1.7178 & 0.0455 & 1.0740 & 0.0005 & 0.1059 \\
\hline S13 & 0.0207 & 0.0229 & 53.7769 & 2.9862 & 0.0281 & 0.7542 & 0.0001 & 0.0633 \\
\hline S14 & 0.0073 & 0.0232 & 51.0264 & 7.8238 & 0.0215 & 1.4368 & 0.0001 & 0.0563 \\
\hline S15 & 0.0052 & 0.0235 & 50.4360 & 12.5956 & 0.0241 & 1.9144 & 0.0004 & 0.0779 \\
\hline
\end{tabular}

Table 6: Input data for cluster 3

\begin{tabular}{|c|c|c|c|c|c|c|c|c|}
\hline Stocks & Return & Risk & RSI & $\mathrm{CV}$ & Alpha & Beta & Liquidity & AHP-weight \\
\hline S1 & 0.0924 & 0.0668 & 53.8029 & 1.7958 & 0.1109 & 1.8737 & 0.0006 & 0.0565 \\
\hline S2 & 0.0915 & 0.0721 & 53.6389 & 1.8909 & 0.1050 & 1.3704 & 0.0008 & 0.0556 \\
\hline S3 & 0.0907 & 0.0873 & 55.4821 & 2.4825 & 0.1368 & 4.6748 & 0.0065 & 0.1258 \\
\hline S4 & 0.0892 & 0.0650 & 53.3348 & 1.7777 & 0.1285 & 3.9862 & 0.0017 & 0.0740 \\
\hline S5 & 0.0883 & 0.0478 & 59.4048 & 1.2688 & 0.1133 & 2.5360 & 0.0007 & 0.0643 \\
\hline S6 & 0.0860 & 0.0669 & 51.9850 & 2.2301 & 0.1070 & 2.1276 & 0.0011 & 0.0620 \\
\hline S7 & 0.0807 & 0.0797 & 54.2527 & 2.4463 & 0.1315 & 5.1498 & 0.0014 & 0.0712 \\
\hline S8 & 0.0805 & 0.0647 & 56.4970 & 1.8872 & 0.0946 & 1.4356 & 0.0049 & 0.0996 \\
\hline S9 & 0.0779 & 0.1038 & 49.7346 & 3.1470 & 0.0907 & 1.3028 & 0.0003 & 0.0444 \\
\hline S10 & 0.1027 & 0.0758 & 54.4138 & 1.9894 & 0.1281 & 2.2159 & 0.0007 & 0.0590 \\
\hline S11 & 0.0740 & 0.0602 & 52.2760 & 2.4143 & 0.0845 & 1.0600 & 0.0010 & 0.0569 \\
\hline $\mathrm{S} 12$ & 0.0734 & 0.0689 & 50.5282 & 4.4138 & 0.0980 & 2.4928 & 0.0004 & 0.0563 \\
\hline S13 & 0.0704 & 0.0790 & 52.5589 & 2.9460 & 0.0972 & 2.7164 & 0.0000 & 0.0478 \\
\hline S14 & 0.0701 & 0.0537 & 55.4624 & 1.8392 & 0.0988 & 2.9051 & 0.0004 & 0.0567 \\
\hline S15 & 0.0698 & 0.0794 & 52.6300 & 3.1823 & 0.1308 & 6.1775 & 0.0011 & 0.0700 \\
\hline
\end{tabular}

\section{Assets Allocation}

The numerical results for each cluster are shown in table 7 .
Table7: Results for each cluster

\begin{tabular}{|l|l|r|r|}
\hline Stock & \multicolumn{1}{|l|}{ cluster 1 } & \multicolumn{1}{l|}{ cluster 2 } & \multicolumn{1}{c|}{ cluster 3 } \\
\hline S1 & 0.0000 & 0.0000 & 0.3994 \\
\hline S2 & 0.0000 & 0.0000 & 0.0635 \\
\hline S3 & 0.0000 & 0.0000 & 0.0725 \\
\hline S4 & 0.0000 & 0.0000 & 0.0622 \\
\hline S5 & 0.0000 & 0.0000 & 0.4024 \\
\hline S6 & 0.0000 & 0.0000 & 0.0000 \\
\hline S7 & 0.0000 & 0.0000 & 0.0000 \\
\hline S8 & 0.0000 & 0.0000 & 0.0000 \\
\hline S9 & 0.0000 & 0.0000 & 0.0000 \\
\hline
\end{tabular}




\begin{tabular}{|l|l|l|l|}
\hline S10 & 0.0000 & 0.0000 & 0.0000 \\
\hline S11 & 0.2153 & 0.0651 & 0.0000 \\
\hline S12 & 0.0354 & 0.5473 & 0.0000 \\
\hline S13 & 0.1188 & 0.1495 & 0.0000 \\
\hline S14 & 0.4398 & 0.2051 & 0.0000 \\
\hline S15 & 0.1907 & 0.0330 & 0.0000 \\
\hline
\end{tabular}

\section{Post-optimality test}

Post optimality test is done using goal programing. Goal programing (GP) is an optimization technique, which was first applied by Charnes, Cooper and Ferguson in 1955 [1] while the actual name first appeared in 1961 by Charnes and Cooper [2]. It is also known as extension of linear programing to solve multiple. It has wide application [19] in finance and for solving portfolio selection problem.

Standard form of GP is as follows:

Minimize $Z=\sum_{j=1} P_{i}\left(d_{i}^{-}+d_{i}^{+}\right)$

Subject to

$\sum_{j=1}^{n} a_{j p} x_{j}+d_{1}^{-}-d_{1}^{+}=b_{i}$
$x_{j} d^{+} d^{-} \geq 0$, for all $\mathrm{i}$ and $\mathrm{j}$.
$d^{+} * d^{-}=0$.
Where
$\mathrm{Z}=$ sum of deviations of all desire goals.
$P_{1}=$ priority weights of goals according to their rank
$d^{+}=$over achievement deviation (slack variable)
$d^{-}=$under achievement deviation (surplus variable).

In this portfolio selection problem, goals are return and risk, the reason behind for taking above-mentioned constraints is that these are basic factors as investor concern about only return and risk. So that the priority weight of goals return and risk having equal value $\left(P_{1}=P_{2}=1\right)$.

Goal 1: to produce maximum return.

Goal 2: to avoid maximum risk.

Since goal is to maximize return and minimize risk so that under achievement $\left(d_{2}^{-}\right)$is not allowed in the case of return and over achievement $\left(d_{2}^{+}\right)$is not allow in the case of risk.

GP model for all three clusters:

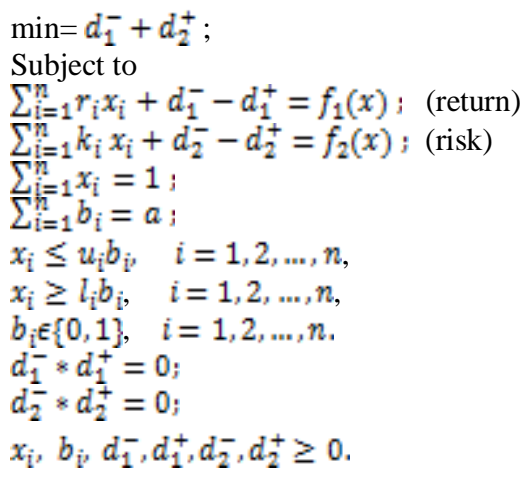

For solving above linear programing, Lingo 12.0 is used. The results are shown in table 8 .

\begin{tabular}{|l|l|l|l|}
\hline \multirow{2}{*}{ Selected stocks } & \multicolumn{3}{|l|}{ Improved ratio } \\
\cline { 2 - 4 } & Cluster 1 & Cluster 2 & Cluster 3 \\
\hline X1 & 0.3770 & 0.3707 & 0.4537 \\
\hline X2 & 0.0225 & 0.5484 & 0.0225 \\
\hline X3 & 0.0225 & 0.0225 & 0.0898 \\
\hline
\end{tabular}

\begin{tabular}{|l|l|l|l|}
\hline X4 & 0.5555 & 0.0225 & 0.0225 \\
\hline $\mathbf{X 5}$ & 0.0225 & 0.0359 & 0.4115 \\
\hline
\end{tabular}

From the above result, it is observed that the new portfolio with improved ratio gives better solution. The result of the clusters is improved by $9.40 \%, 0.89 \%$ and $0.06 \%$ respectively as compared to those results, which has been obtained from BBO.

\section{Conclusion}

This paper develops a hybrid approach for portfolio selection and presented a post optimality test for improving obtained results. Methodology for portfolio selection is involved Behavior Survey, Cluster Analysis, AHP, BBO algorithm which takes less execution time as compare to other optimization technique. Cluster analysis done by $\mathrm{X}$-means algorithm, which generates actual number of cluster according to the data. Because in X-means there is no need to define number of cluster, it decides itself. [20] The purpose of this paper is to address goal programing for post optimality test that can be improve the result. After portfolio selection, an optimality test applied on the selected stocks to get new and improved proportion of stocks.[21] However, in every case, improvement in the proportion is not necessarily. If the selected portfolio is optimum, then there is no change in the solution otherwise better proportion of the stocks can be evaluated by the proposed optimality test.

\section{References}

[1] A. Charnes and W.W. Cooper, "Management models and industrial applications of linear programing", Wiley, New York. No. 339.23 C4. 1961.

[2] A. Charnes, W.W. Cooper and R Ferguson, "Optimal estimation of executive compensation by linear programing", Management Science 1 (2) (1955) 138-151.

[3] A. Ghahtarani and A.A. Najafi, "Robust goal programing for multi-objective portfolio selection problem", Economic Modelling 33 (2014) 588-592.

[4] A. Jagongo and V.S. Mutswenje, "A survey of the factors influencing investment decisions: The case of individual investors at the NSE", International Journal of Humanities and Social Science 4 (4) (2014) 92-102

[5] Akhpanov, S. Sabitov, R. Shaykhadenov (2018). Criminal pre-trial proceedings in the Republic of Kazakhstan: Trend of the institutional transformations. Opción, Año 33. 107-125.

[6] D. Dubois and H. Prade, "Possibility theory: qualitative and quantitative aspects", Quantified representation of uncertainty and imprecision. Springer, Dordrecht (1998) 169-226.

[7] D. Pelleg, A. Moore, "X-means: Extending K-means with efficient estimation of the number of clusters", Proceeding $17^{\text {th }}$ International conference on Machine Learning, 2000 727-734.

[8] D. Simon, "Biogeography-based optimization", IEEE Transection on Evolutionary Computation 12 (6) (2008) 702-713.

[9] D. Panwar, M. Jha and N. Srivastava, "Portfolio selection using biogeographic-based optimization and forecasting", Journal of Advanced Research in Dynamical Control System 10 (6) (2018) 852-863.

[10] H. Markowitz, "Portfolio selection", The Journal of Finance 7 (1) (1952) 77-91.

[11] H. Konno and H. Yamazaki, "Mean absolute deviation portfolio optimization model and its application to Tokyo stock market", Journal of Management Science 37 (5) (1991) 519-531.

[12] L.A. Zadeh, "Fuzzy set as a basis for a theory of possibility", Fuzzy Set and System 1 (1978) 3-28.

[13] L.W. Siew and L.W. Hoe, "Strategic decision making in portfolio management with goal programing model", American Journal of Operations Management and Information System 1 (1) (2016) 3438. 
[14] M. G. Speranza, "Linear programming models for portfolio optimization", Journal of Finance 14 (1993) 107-123.

[15] M. Masmoudi and F.B. Abdelaziz, "Arecourse goal programing approach for the portfolio selection problem", Information System and Operation Research 50 (3) (2012) 134-139.

[16] M. Tamiz and R.A. Azmi, "Goal programing with extended factors for portfolio selection", International Transactions in Operational Research, 2017. Doi.org/10.1111/itor.12423

[17] S.J. Stoyan and R.H. Kwon, "A stochastic goal mixed integer programing approach for integrated stock and bond portfolio optimization", Computer and Industrial Engineering 61 (4) (2011) 1285 1295.

[18] G Abilbakieva, M Knissarina, K Adanov, S Seitenova, G Bekeshova (2018). Managerial competence of future specialists of the education system (Preschool education and upbringing) and medicine in the comparative aspect. Opción, Año 33, No. 85. 4462.

[19] T.L. Saaty, "The analytic hierarchy process", McGraw-Hill, New York, 1980.

[20] T. Hasuike and H. Katagiri, "Sensitivity analysis for portfolio selection problem considering investor's subjectivity", Proceeding of the International Multi Conference of Engineering and Computer Scientist, March 17-19, 2010, Hong Kong.

[21] T.W. Lin and D.E.O. Leary, "Goal programing application in financial management", Advances in Mathematical Programing and Financial Planning 3 (1993) 211-229. 